\title{
Review Article \\ Platelet-Rich Fibrin as a Biofuel for Tissue Regeneration
}

\author{
Sujeet Vinayak Khiste and Ritam Naik Tari \\ Department of Periodontology, Tatyasaheb Kore Dental College and Research Centre, New Pargaon, Kolhapur, \\ Maharashtra 416137, India \\ Correspondence should be addressed to Sujeet Vinayak Khiste; drsujeetperio@gmail.com
}

Received 17 April 2013; Accepted 20 May 2013

Academic Editors: W.-C. Chen, S. Lamponi, V. Larreta-Garde, and B. Yang

Copyright (c) 2013 S. V. Khiste and R. Naik Tari. This is an open access article distributed under the Creative Commons Attribution License, which permits unrestricted use, distribution, and reproduction in any medium, provided the original work is properly cited.

Wound healing is a staged process which involves the activity of leukocytes and platelets. For this process to work efficiently, the platelets play a vital role. The growth factors present in platelets are important to guide the regenerating cells to the area of healing. Platelet-rich-fibrin (PRF) is one such material that holds on to these growth factors enmeshed in the fibrin network resulting in their sustained release over a period of time that can accelerate the wound healing process. With this knowledge, research has been carried out for a past few years for the clinical application of PRF. Various platelet concentrates have been studied including the platelet-rich-plasma (PRP). However, the short duration of cytokine release and its poor mechanical properties have resulted in the search of a new material with adequate properties for clinical application and ease of preparation. PRF has found a place in the regenerative field owing to its advantages over PRP. This review focuses on the properties and various applications of PRF in the clinical practice.

\section{Introduction}

Excogitation in the concept of tissue engineering has brought about a drastic improvement in the healing response of tissues. Various pathological etiologies result in dysfunction of the oral tissues and creation of bony defects, thus affecting the quality of life in these patients. The pivotal goal in periodontal and maxillofacial tissue regeneration is to reconstruct these defects which led to the search of a biofuel [1]. Focus has constantly been on devising a "wonder material" that is most effective in its regenerative potential. Various platelet-derived products or platelet concentrates have been introduced that act as biological mediators aiding the healing response. Platelet-rich fibrin (PRF) is one such product that has proved its worth and has edged past the others. The Choukroun's platelet rich fibrin has opened the flood-gates in the field of dentistry, majorly focusing on the improved healing and regeneration [2]. Thus PRF has also been tagged as a healing biomaterial [2].

The world of medicine was acquainted with the regenerative potential of platelets in 1974 . The platelet concentrates have been used for the improvement of reparation and regeneration of the soft and hard tissues after various periodontal surgical procedures. Using platelet concentrates is a way to accelerate and enhance the body's natural wound healing mechanisms [2]. PRF is a second-generation platelet concentrate widely used to accelerate soft and hard tissue healing and is a strictly autologous fibrin matrix containing a large quantity of platelet and leukocyte cytokines [3]. Ross et al. were amongst the pioneers who first described a growth factor from platelets. Growth factors are released after activation from the platelets trapped within fibrin matrix and have been shown to stimulate the mitogenic response in the periosteum for bone repair during normal wound healing [2]. Choukroun's PRF has been the latest development among the platelet concentrates. This paper intends to review the potential of PRF in the field of periodontal regeneration.

\section{Evolution of Various Platelet Concentrates}

The healing of hard and soft tissue is mediated by a wide range of intra- and extracellular events that are regulated by signaling proteins. Although the knowledge about these molecules remains incomplete, platelets have been found to play a crucial role not only in hemostasis, but also in the wound healing process [4]. 
Platelets are anucleate cytoplasmic fragments containing $\alpha$-granules that are spherical or oval structures with diameters ranging from 200 to $500 \mathrm{~nm}$ [5]. They form an intracellular storage pool of proteins vital to wound healing, including platelet-derived growth factor (PDGF), transforming growth factor (TGF $\beta$ ), and insulin-like growth factor (IGF-I). Secretion of the active proteins follows the fusion of the granules with the platelet cell membrane, which subsequently bind to the transmembrane receptors of the target cells [5].

Numerous techniques of autologous platelet concentrates have been developed and applied in oral and maxillofacial surgery. The first generation incorporates the platelet-rich plasma while the second generation involves the platelet-rich fibrin.

2.1. Platelet-Rich Plasma (PRP). Platelet-rich plasma was introduced for the first time by Marx et al. in 1998 [6]. PRP was used in mandibular reconstructions along with cancellous bone marrow grafts. The data reported by Marx suggested that PRP addition accelerated the rate and degree of bone formation [6]. PRP was developed to combine the fibrins sealant properties with growth factor effects of platelets, thus providing an ideal growth factor delivery system at the site of injury. These Growth factors exhibit chemotactic and mitogenic properties that promote and modulate cellular functions involved in tissue healing, regeneration, and cell proliferation [7].

\subsection{Clinical Applications $[8,9]$}

(1) In sinus lift procedures, PRP accelerates the healing and reduces the healing time with stable bone gain.

(2) Ridge augmentation can be achieved with the use of PRP.

(3) Socket preservation to maintain the alveolar bone height is possible.

(4) Intrabony defects or osseous defects have shown bone fill with the use of PRP.

(5) Jaw reconstruction surgeries.

(6) Soft tissue procedures like gingival grafts, subepithelial grafts, and so forth, because of the property of PRP of accelerating soft tissue healing.

\subsection{Limitations [10]}

(1) Lack of uniformity in PRP preparation protocol as different platelet concentrations have different storage time.

(2) Release of growth factors for a shorter period of time.

(3) Antibodies to bovine factor Va may cross react with human factor Va and may produce coagulopathies and rare bleeding episodes.

\section{Platelet-Rich Fibrin (PRF)}

3.1. Concept and Evolution of PRF: A Second-Generation Platelet Derivative. Developed in France by Choukroun et al. in 2001, PRF is a second-generation platelet derivative because, unlike other platelet concentrates like PRP, this technique does not require anticoagulants nor bovine thrombin or any other gelifying agent. PRF is a strictly autologous fibrin matrix containing a large quantity of platelet and leukocyte cytokines [3]. PRF represents a novel measure in the therapeutic concept with elementary processing and absence of artificial biochemical modification like the use of bovine thrombin [11].

The crux of PRF synthesis lies in the attempt to accumulate platelets and release cytokines in a fibrin clot (Table 1). The PRF clot is yielded by a natural polymerization process during centrifugation, and its natural fibrin architecture seems responsible for a slow release of growth factors and matrix glycoproteins during $\geq 7$ days [12]. Such a slow release is unimaginable to point out in most PRP techniques because of their brutal platelet activation, contiguous release of growth factors, and very light fibrin network produced to sustain the concentrate injection [13].

\section{Biologic Features: Growth Factors Present in PRF, Leucocyte Activation}

PRF dwells among a new generation of platelet concentrate that jump-starts the healing process to maximize predictability. It consists of the platelets, cytokines, and the fibrin matrix. Platelets and leukocyte cytokines play an important part in the biology of this biomaterial [5]. Degranulation of platelets entails the release of cytokines able to stimulate cell migration and proliferation within the fibrin matrix, launching the first stages of healing $[2,3]$. Fibrin matrix supporting them constitutes the determining element responsible for the real therapeutic potential of PRF. The biologic activity of the fibrin molecule highlights its significant cicatricial capacity [2].

However, a detailed understanding of the constituents of PRF and their biological role will help understand this biomaterial from a clinical standpoint and subsequently extend the fields of therapeutic applications.

\section{Functions and Role of Fibrin Matrix}

Fibrin is an activated form of fibrinogen molecule present in plasma as well as the $\alpha$-granules of platelets. It plays a significant role in platelet aggregation and achievement of hemostasis. The soluble fibrinogen is transformed into insoluble fibrin that polymerizes to a cicatricial matrix [18]. The slow and natural polymerization of fibrin results in its homogenous 3-dimensional organization during the centrifugation performed in PRF preparation. This leads to the intrinsic incorporation of platelet cytokines and glycan chains in the fibrin meshes [18]. The fibrin matrix present in PRF is flexible, elastic, and very strong [19]. It consists of weak thrombin concentrations which entails equilateral junctions. These connected junctions permit the ecesis of a fine and flexible fibrin network capable of supporting cytokines and cellular migration that occurs. This results in an increase in the life span of these cytokines as their release and use will occur at the time of initial cicatricial matrix remodeling. 
TABLE 1: Cytokines present in PRF and their functions.

\begin{tabular}{|c|c|}
\hline Cytokines present in PRF & Functions \\
\hline Transforming growth factor- $\beta$ (TGF- $\beta$ ) & $\begin{array}{l}\text { (i) Released from } \alpha \text {-granules of platelets } \\
\text { (ii) Stimulates proliferation of osteoblasts [14] } \\
\text { (iii) Synthesis of collagen type I and fibronectin } \\
\text { (iv) Enhanced woven bone formation } \\
\text { (v) Enhanced chemotaxis of osteoblast cells } \\
\text { (vi) Stimulates angiogenesis }\end{array}$ \\
\hline Platelet-derived growth factor (PDGF) & $\begin{array}{l}\text { (i) Migration and proliferation of mesenchymal lineage cells [15] } \\
\text { (ii) Angiogenic effect on endothelial cells [16] }\end{array}$ \\
\hline Vascular endothelial growth factor (VEGF) & (i) Initiates angiogenesis [2] \\
\hline Insulin growth factor-1 (IGF-1) & $\begin{array}{l}\text { (i) Stimulates osteoblast proliferation [16] } \\
\text { (ii) Chemotactic effects towards human osteoblasts } \\
\text { (iii) Increased expression of osteocalcin } \\
\text { (iv) Enhances wound healing }\end{array}$ \\
\hline Fibroblast growth factor (FGF) & $\begin{array}{l}\text { (i) Stimulates osteoblast proliferation [16] } \\
\text { (ii) Chemotactic effects towards human osteoblasts } \\
\text { (iii) Increased expression of osteocalcin } \\
\text { (iv) Enhances wound healing }\end{array}$ \\
\hline Epidermal growth factor (EGF) & $\begin{array}{l}\text { (i) Stimulation of cell proliferation and extracellular matrix turnover [17] } \\
\text { (ii) Chemotactic effect on periodontal fibroblast cells }\end{array}$ \\
\hline
\end{tabular}

Thus, the cytokines are made available for a mandatory period required by the cells to initiate the healing [19].

Fibrin meshwork in PRF differs from that in PRP. In PRP, there are bilateral junctions resulting in a rigid network that does not honor the cytokine enmeshment and cellular migration. The increased thrombin required for rapid setting of the PRP leads to a rigid polymerized material [19].

5.1. Role of Fibrin in Angiogenesis. Entrapment of cytokines in the 3-dimensional architecture of fibrin matrix results in their sustained release which is monumental in initiation of angiogenesis [20].

The cytokines responsible for this action include the FGF, VEGF, angiopoietin, and PDGF within the fibrin gel. It is the rigidity of the fibrin matrix that is instrumental in the process of angiogenesis in response to FGF and VEGF stimulation [21].

Increased expression of $\alpha \mathrm{v} \beta 3$ integrin in response to fibrin allows the binding of endothelial cells to fibrin itself, fibronectin, and vitronectin [22].

5.2. Fibrin Assisted Immune Response. Increased expression of CD11c/CD18 receptor on endothelial cells by fibrin aids in enhanced adhesion to endothelial cells and fibrinogen, and transmigration of neutrophils [23]. Fibrin and fibronectin also modulate the wound colonization by the macrophages.

5.3. Effect of Fibrin on Mesenchymal Stem Cells. Fibrin matrix acts as a scaffold for the undifferentiated mesenchymal cells that facilitate the differentiation of these cells thus aiding in tissue regeneration [13].

5.4. Effect of Fibrin on Osseous Tissue. Direct interaction between fibrin and the osseous tissue lacks significant documentation. However, bone morphogenic proteins enmeshed in fibrin matrix have the ability to be released consistently highlighting the angiogenic, hemostatic, and osteoconductive properties [24]. Fibrin is accredited as a support matrix for BMP. BMPs enmeshed in fibrin are progressively released and are able to induce bone. Consistent release of VEGF, FGF and PDGF helps in angeiogenesis. Hemostasis is achieved through the ability of fibrin clot to trap circulating stem cells, allowing vascular and tissue restoration [24].

\section{Preparation}

Preparation of PRF follows the protocol developed by Choukroun et al. in Nice, France [25]. The protocol for PRF preparation is very simple; however it has to be manufactured just prior to its application.

Requirements:

(i) table centrifuge,

(ii) 10-mL dry glass test tube (without anticoagulant),

(iii) blood collection armamentarium.

The main advantages in PRF preparation are the singlestage centrifugation and absence of bovine thrombin. The blood obtained from the subject is placed into the test tube and centrifuged immediately for 10 minutes at $3000 \mathrm{rpm}$ [18]. Others have used $2700 \mathrm{rpm}$ for 12 minutes with similar findings [26].

The steps involved are as follows:

(1) blood specimen is collected or drawn from the patient,

(2) the blood specimen is placed in the centrifuge and is allowed to spin immediately for the stipulated time,

(3) following this the blood sample settles into various layers. 
The absence of any anticoagulant grants the activation of platelets to set off a coagulation cascade. Due to the absence of the anticoagulant, the blood coagulates immediately upon contact with the glass tube. Initially, fibrinogen occupies the upper part of the tube, only till the circulating thrombin transforms it into a fibrin network [3].

The layers that are formed are as follows:

(a) the lower fraction containing the RBCs,

(b) the middle fraction containing the fibrin clot,

(c) the upper fraction containing the straw-colored acellular plasma.

The upper portion of the test tube containing the acellular plasma is removed. The middle portion containing the fibrin clot is then removed and is scrapped off from the lower part containing the red blood cells. The natural and progressive polymerization results in a fibrin clot formation with substantial embedding of platelets and leukocyte growth factors into the fibrin matrix [27].

\section{PRF Membrane}

The clot can be squeezed between two gauge pieces to obtain an inexpensive autologous fibrin membrane [3]. The serum exudate expressed from the clot is rich in proteins such as vitronectin and fibronectin [28]. This exudate may be used to hydrate graft materials, rinse the surgical site, and store autologous graft [3].

The PRF Box (Process Ltd., Nice, France) is commercially available to prepare the PRF membrane. The PRF clot is placed on the grid in the PRF box and covered with compressor lid which squeezes out the fluid from the clot. The membranes formed using this method had constant thickness which remain hydrated for several hours and have recovered the serum exudate expressed from the fibrin clots.

\section{Clinical Implications of PRF}

\subsection{Oral Applications}

(1) PRF and PRF membrane have been used in combination with bone grafts to hasten the healing in lateral sinus floor elevation procedures [29].

(2) Protection and stabilization of graft materials during ridge augmentation procedures [30].

(3) Socket preservation after tooth extraction or avulsion [31].

(4) PRF membrane has been used for root coverage with single and multiple teeth recession [32].

(5) Regenerative procedures in treatment of 3-walled osseous defect.

(6) In the treatment of combined periodontic endodontic lesion.

(7) Treatment of furcation defect [33].

(8) PRF enhances palatal wound healing after free gingival graft [34].

(9) Filling of cystic cavity.

\section{Extraoral Clinical Applications}

Use of PRF in periodontology and oral and maxillofacial surgery has been largely described.

(1) PRF promotes dentinogenesis by stimulating cell proliferation and differentiation of Dental Pulp Cells [35].

(2) To augment Achilles tendon repair [36, 37].

(3) PRFM can provide significant long-term diminution of deep nasolabial folds [38].

(4) Application in facial plastic surgery $[39,40]$ :

(i) nasolabial folds,

(ii) facial volumization,

(iii) superficial rhytides,

(iv) acne scars,

(v) rhinoplasty,

(vi) facial esthetic lipostructure,

(vii) autologous fat transfer,

(viii) rhytidectomy,

(ix) depressed scar,

(x) dermal augmentation.

(5) Healing of severe nonhealing lower-extremity ulcers [41].

(6) Repair of articular cartilage defects [42].

PRF membrane functionalized by incorporation alkaline phosphatase induces the mineralization of PRF. Thus, PRF can also be a suitable material for bone replacement [43].

9.1. Why Use PRF? PRF is an adjunct to the natural healing process and has the following effects:

(a) the fibrin clot acts as a support through its mechanical properties which involve the protection of graft materials and also acts as a biological connector between the bone particles,

(b) in addition to this the fibrin network is engaged in cellular migration, mainly for the endothelial cells necessary for the neoangiogenesis, vascularization, and survival of the graft,

(c) the process of healing is carried along and aided by the persistent release of various growth factors that include PDGF, TGF- $\beta$ and IGF-1,

(d) the presence of leukocytes and various cytokines enables the self-regulation of the infectious and inflammatory processes.

Table 2 enlists the advantages and shortcomings associated with the use of PRF. 
TABLE 2: Advantages and shortcomings of PRF.

\begin{tabular}{|c|c|}
\hline Advantages of PRF & Shortcomings of PRF \\
\hline (i) No use of anticoagulants & $\begin{array}{l}\text { (i) Rapid use of the PRF } \\
\text { without delay or short } \\
\text { handling time }\end{array}$ \\
\hline (ii) Slow natural polymerization & $\begin{array}{l}\text { (ii) Low quantity of PRF is } \\
\text { obtained }\end{array}$ \\
\hline $\begin{array}{l}\text { (iii) } 3 \mathrm{D} \text { fibrin network forming a } \\
\text { matrix aiding in cytokine } \\
\text { retention for extended periods }\end{array}$ & \\
\hline $\begin{array}{l}\text { (iv) Formulation of a PRF } \\
\text { membrane that possesses } \\
\text { elasticity and flexibility }\end{array}$ & \\
\hline (v) Simple and cost effective & \\
\hline
\end{tabular}

\subsection{Limitations of $P R F$}

(1) Owing to the fact that PRF is an autologous product, the availability of this biomaterial in larger amounts is a concern. Hence, its usage in surgical procedures should be well supervised [23].

(2) PRF possesses the circulating immune cells and antigenic molecules that prevent its use as an allogenic material [23]. Also, there is an increased risk of transmitting infectious agents.

\section{Conclusion}

The application of autologous platelet-rich fibrin could present new possibilities for enhanced healing and functional recovery. However, the effectiveness of PRF in regenerative procedures should be evaluated in studies that involve a large number of subjects. Moreover, the use of PRF in randomized control trials has to be encouraged.

\section{Conflict of Interests}

The authors of the paper do not have any direct financial relation with any commercial identity mentioned in the paper that might lead to any conflict of interests.

\section{References}

[1] V. Gassling, T. Douglas, P. H. Warnke, Y. Açil, J. Wiltfang, and S. T. Becker, "Platelet-rich fibrin membranes as scaffolds for periosteal tissue engineering," Clinical Oral Implants Research, vol. 21, no. 5, pp. 543-549, 2010.

[2] V. Gupta, V. K. Bains, G. P. Singh, A. Mathur, and R. Bains, "Regenerative potential of platelet rich fibrin in dentistry: literature review," Asian Journal of Oral Health and Allied Sciences, vol. 1, no. 1, pp. 22-28, 2011.

[3] M. Toffler, N. Toscano, D. Holtzclaw, M. Del Corso, and D. D. Ehrenfest, "Introducing Choukroun's platelet rich fibrin (PRF) to the reconstructive surgery milieu," The Journal of Implant and Advanced Clinical Dentistry, vol. 1, no. 6, pp. 21-32, 2009.

[4] V. L. W. Gasling, Y. Acil, I. N. Springer, N. Hubert, and J. Wiltfag, "Platelet-rich plasma and platelet-rich fibrin in human cell culture," Oral Surgery, Oral Medicine, Oral Pathology, Oral Radiology, and Endodontics, vol. 108, pp. 45-48, 2009.

[5] S. Prakash and A. Thakur, "Platelet concentrates: past, present and future," Journal of Oral and Maxillofacial Surgery, vol. 10, no. 1, pp. 45-49, 2011.

[6] R. E. Marx, E. R. Carlson, R. M. Eichstaedt, S. R. Schimmele, J. E. Strauss, and K. R. Georgeff, "Platelet-rich plasma: growth factor enhancement for bone grafts," Oral Surgery, Oral Medicine, Oral Pathology, Oral Radiology, and Endodontics, vol. 85, no. 6, pp. 638-646, 1998.

[7] E. Anitua, M. Sánchez, G. Orive, and I. Andía, "The potential impact of the preparation rich in growth factors (PRGF) in different medical fields," Biomaterials, vol. 28, no. 31, pp. 45514560, 2007.

[8] S. J. Froum, S. S. Wallace, D. P. Tarnow, and S. Cho, "Effect of platelet-rich plasma on bone growth and Osseointegration in human maxillary sinus grafts: three bilateral case reports," International Journal of Periodontics and Restorative Dentistry, vol. 22, no. 1, pp. 45-53, 2002.

[9] N. S. Arora, T. Ramanayke, Y. F. Ren, and G. E. Romanos, "Platelet-rich plasma: a literature review," Implant Dentistry, vol. 18, no. 4, pp. 303-308, 2009.

[10] R. E. Marx, "Platelet rich plasma: evidence to support its use," Journal of Oral and Maxillofacial Surgery, vol. 64, pp. 489-496, 2004.

[11] D. M. Dohan, J. Choukroun, A. Diss et al., "Platelet-rich fibrin (PRF): a second-generation platelet concentrate. Part I: technological concepts and evolution," Oral Surgery, Oral Medicine, Oral Pathology, Oral Radiology and Endodontology, vol. 101, no. 3, pp. E37-E44, 2006.

[12] D. M. Dohan Ehrenfest, G. M. de Peppo, P. Doglioli, and G. Sammartino, "Slow release of growth factors and thrombospondin-1 in Choukroun's platelet-rich fibrin (PRF): a gold standard to achieve for all surgical platelet concentrates technologies," Growth Factors, vol. 27, no. 1, pp. 63-69, 2009.

[13] J. Choukroun, A. Diss, A. Simonpieri et al., "Platelet-rich fibrin (PRF): a second-generation platelet concentrate. Part IV: clinical effects on tissue healing," Oral Surgery, Oral Medicine, Oral Pathology, Oral Radiology and Endodontology, vol. 101, no. 3, pp. E56-E60, 2006.

[14] W. V. Giannobile, R. A. Hernandez, R. D. Finkelman et al., "Comparative effects of platelet-derived growth factor-BB and insulin-like growth factor-I, individually and in combination, on periodontal regeneration in Macaca fascicularis," Journal of Periodontal Research, vol. 31, no. 5, pp. 301-312, 1996.

[15] E. Lucarelli, A. Beccheroni, D. Donati et al., "Platelet-derived growth factors enhance proliferation of human stromal stem cells," Biomaterials, vol. 24, no. 18, pp. 3095-3100, 2003.

[16] V. Sunitha Raja and E. Munirathnam Naidu, "Platelet-rich fibrin: evolution of a second-generation platelet concentrate," Indian Journal of Dental Research, vol. 19, no. 1, pp. 42-46, 2008.

[17] V. Moulin, "Growth factors in skin wound healing," European Journal of Cell Biology, vol. 68, no. 1, pp. 1-7, 1995.

[18] D. M. Dohan, J. Choukroun, A. Diss et al., "Platelet-rich fibrin (PRF): a second-generation platelet concentrate. Part III: leucocyte activation: a new feature for platelet concentrates?" Oral Surgery, Oral Medicine, Oral Pathology, Oral Radiology and Endodontology, vol. 101, no. 3, pp. E51-E55, 2006.

[19] M. W. Mosesson, K. R. Siebenlist, and D. A. Meh, "The structure and biological features of fibrinogen and fibrin," Annals of the New York Academy of Sciences, vol. 936, pp. 11-30, 2001. 
[20] H. F. Dvorak, V. S. Harvey, P. Estrella, L. F. Brown, J. McDonagh, and A. M. Dvorak, "Fibrin containing gels induce angiogenesis. Implications for tumor stroma generation and wound healing," Laboratory Investigation, vol. 57, no. 6, pp. 673-686, 1987.

[21] V. Nehls and R. Herrmann, "The configuration of fibrin clots determines capillary morphogenesis and endothelial cell migration," Microvascular Research, vol. 51, no. 3, pp. 347-364, 1996.

[22] X. Feng, R. A. F. Clark, D. Galanakis, and M. G. Tonnesen, "Fibrin and collagen differentially regulate human dermal microvascular endothelial cell integrins: stabilization of $\alpha \mathrm{v} / \beta 3$ mRNA by fibrin," Journal of Investigative Dermatology, vol. 113, no. 6, pp. 913-919, 1999.

[23] J. D. Loike, B. Sodeik, L. Cao et al., "CD11c/CD18 on neutrophils recognizes a domain at the $\mathrm{N}$ terminus of the $\mathrm{A} \alpha$ chain of fibrinogen," Proceedings of the National Academy of Sciences of the United States of America, vol. 88, no. 3, pp. 1044-1048, 1991.

[24] M. Kawamura and M. R. Urist, "Human fibrin is a physiologic delivery system for bone morphogenetic protein," Clinical Orthopaedics and Related Research, no. 235, pp. 302-310, 1988.

[25] T. R. Appel, B. Pötzsch, J. Müller, J. von Lindern, S. J. Bergé, and R. H. Reich, "Comparison of three different preparations of platelet concentrates for growth factor enrichment," Clinical Oral Implants Research, vol. 13, no. 5, pp. 522-528, 2002.

[26] N. K. Kiran, K. S. Mukunda, and T. N. Tilakraj, "Platelet concentrates: a promising innovation in dentistry," Journal of Dental Sciences and Research, vol. 2, no. 1, pp. 50-61, 2011.

[27] D. M. Dohan Ehrenfest, L. Rasmusson, and T. Albrektsson, "Classification of platelet concentrates: from pure platelet-rich plasma (P-PRP) to leucocyte- and platelet-rich fibrin (L-PRF)," Trends in Biotechnology, vol. 27, no. 3, pp. 158-167, 2009.

[28] D. M. Dohan, J. Choukroun, A. Diss et al., "Platelet-rich fibrin (PRF): a second-generation platelet concentrate. Part II: platelet-related biologic features," Oral Surgery, Oral Medicine, Oral Pathology, Oral Radiology and Endodontology, vol. 101, no. 3, pp. E45-E50, 2006.

[29] J. Choukroun, A. Diss, A. Simonpieri et al., "Platelet-rich fibrin (PRF): a second-generation platelet concentrate. Part V: histologic evaluations of PRF effects on bone allograft maturation in sinus lift," Oral Surgery, Oral Medicine, Oral Pathology, Oral Radiology and Endodontology, vol. 101, no. 3, pp. 299-303, 2006.

[30] J. D. Kassolis, P. S. Rosen, and M. A. Reynolds, "Alveolar ridge and sinus augmentation utilizing platelet-rich plasma in combination with freeze-dried bone allograft: case series," Journal of Periodontology, vol. 71, no. 10, pp. 1654-1661, 2000.

[31] M. Del Corso, M. Toffler, and D. M. D. Ehrenfest, "Use of autologous leukocyte and platelet-rich fibrin (L-PRF) membrane in post-avulsion sites," The Journal of Implant and Advanced Clinical Dentistry, vol. 1, no. 9, pp. 27-35, 2010.

[32] A. Kumar, B. Fernandes, and C. Surya, "Platelet-rich fibrin: a promising approach for root coverage," Journal of Interdisciplinary Dentistry, vol. 1, no. 2, pp. 115-118, 2011.

[33] A. Sharma and A. R. Pradeep, "Autologous platelet-rich fibrin in the treatment of mandibular degree II furcation defects: a randomized clinical trial," Journal of Periodontology, vol. 82, no. 10, pp. 1396-1403, 2011.

[34] V. Jain, M. G. Triveni, A. B. T. Kumar, and D. S. Mehta, "Role of platelet rich fibrin in enhancing palatal wound healing after free gingival graft," Contemporary Clinical Dentistry, vol. 3, pp. S240-S243, 2012.

[35] F. Huang, S. Yang, J. Zhao, and Y. Chang, "Platelet-rich fibrin increases proliferation and differentiation of human dental pulp cells," Journal of Endodontics, vol. 36, no. 10, pp. 1628-1632, 2010.
[36] T. L. Sarrafian, H. Wang, E. S. Hackett et al., "Comparison of achilles tendon repair techniques in a sheep model using a cross-linked acellular porcine dermal patch and platelet-rich plasma fibrin matrix for augmentation," Journal of Foot and Ankle Surgery, vol. 49, no. 2, pp. 128-134, 2010.

[37] M. Sánchez, E. Anitua, J. Azofra, I. Andía, S. Padilla, and I. Mujika, "Comparison of surgically repaired Achilles tendon tears using platelet-rich fibrin matrices," The American Journal of Sports Medicine, vol. 35, no. 2, pp. 245-251, 2007.

[38] A. P. Sclafani, "Platelet-rich fibrin matrix for improvement of deep nasolabial folds," Journal of Cosmetic Dermatology, vol. 9, no. 1, pp. 66-71, 2010.

[39] A. P. Sclafani, "Safety, efficacy, and utility of platelet-rich fibrin matrix in facial plastic surgery," Archives of Facial Plastic Surgery, vol. 13, no. 4, pp. 247-251, 2011.

[40] F. Braccini and D. M. Dohan, "The relevance of Choukroun's Platelet Rich Fibrin (PRF) during facial aesthetic lipostructure (Coleman's technique): preliminary results," Revue de Laryngologie Otologie Rhinologie, vol. 128, no. 4, pp. 255-260, 2007.

[41] S. M. O’Connell, T. Impeduglia, K. Hessler, X. Wang, R. J. Carroll, and H. Dardik, "Autologous platelet-rich fibrin matrix as cell therapy in the healing of chronic lower-extremity ulcers," Wound Repair and Regeneration, vol. 16, no. 6, pp. 749-756, 2008.

[42] A. M. Haleem, A. A. Singergy, D. Sabry et al., "The clinical use of human culture-expanded autologous bone marrow mesenchymal stem cells transplanted on platelet-rich fibrin glue in the treatment of articular cartilage defects: a pilot study and preliminary results," Cartilage, vol. 1, no. 4, pp. 253-261, 2010.

[43] T. E. L. Douglas, V. Gassling, H. A. Declercq et al., "Enzymatically induced mineralization of platelet-rich fibrin," Journal of Biomedical Materials Research, vol. 100A, pp. 1335-1346, 2012. 

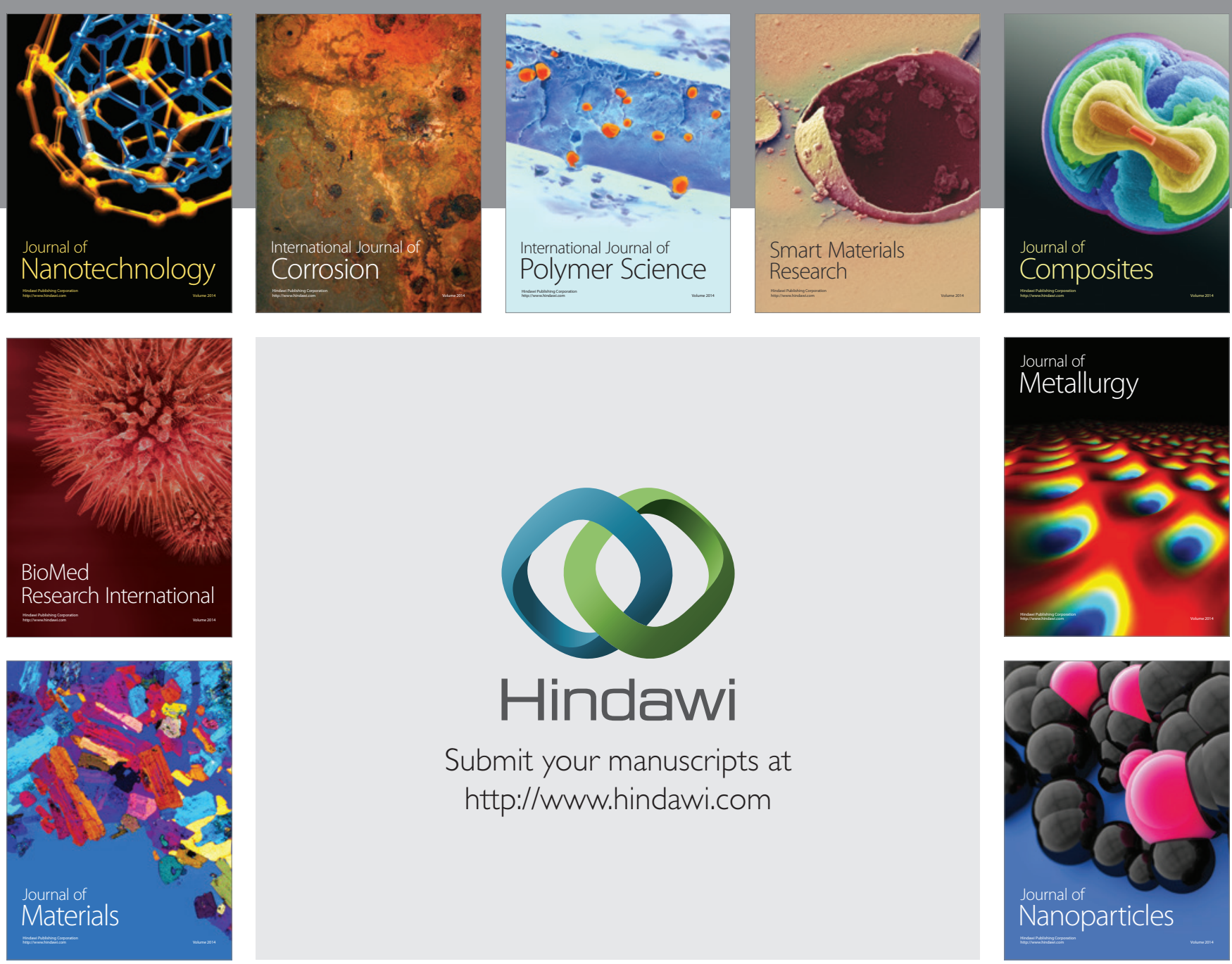

Submit your manuscripts at http://www.hindawi.com
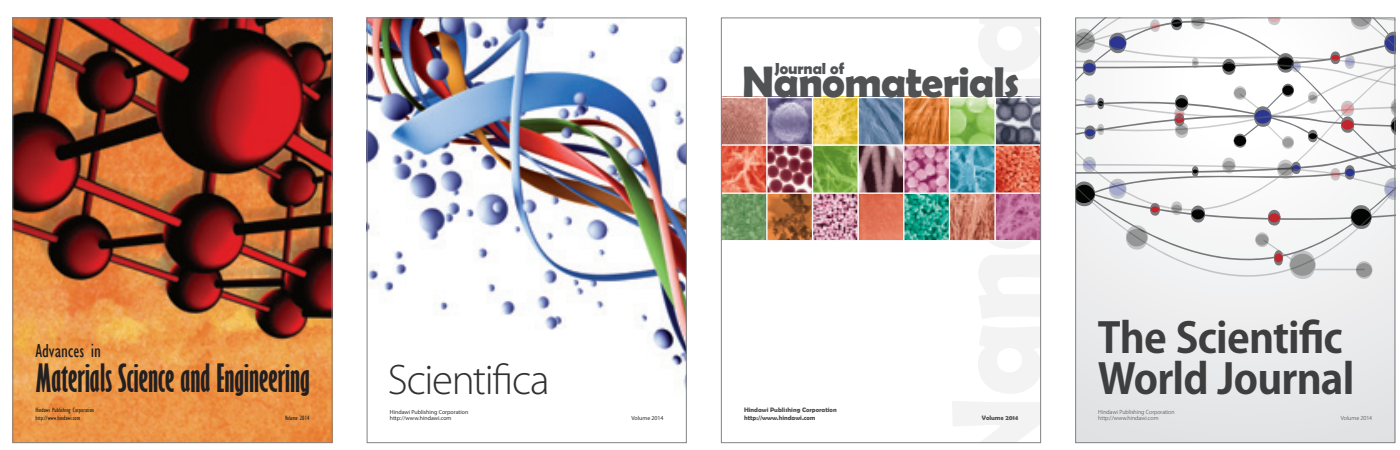

\section{The Scientific World Journal}
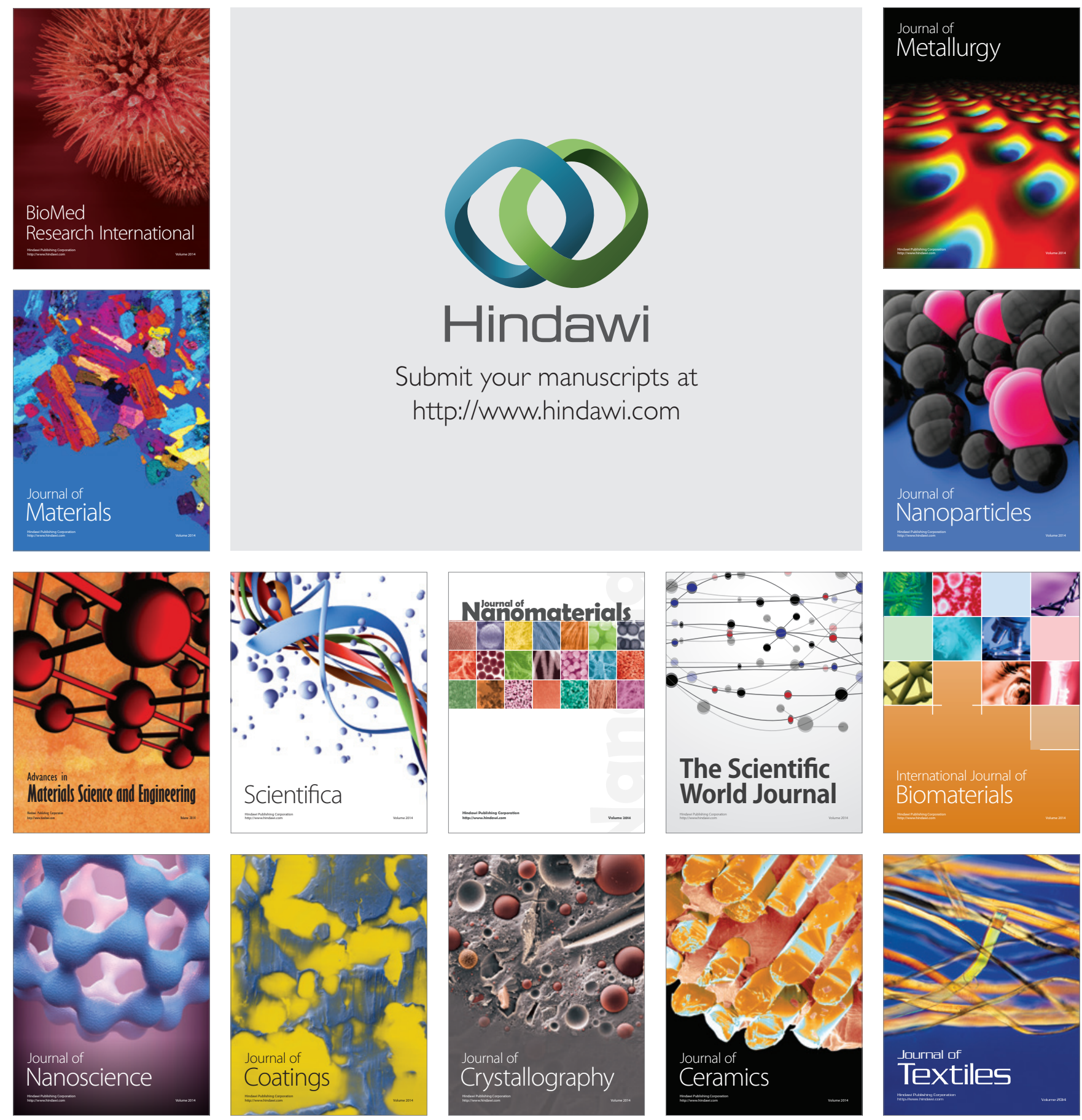